\title{
Effects of Bird Traits on Seed Dispersal of Endangered Taxus chinensis (Pilger) Rehd. with Ex-Situ and In-Situ Conservation
}

\author{
Ning $\mathrm{Li}^{1, *}{ }^{10}$, Zheng Wang ${ }^{2}$, Xin-Hai $\mathrm{Li}^{3}$, Xian-Feng $\mathrm{Yi}^{4}{ }^{4}$, Chuan $\mathrm{Yan}^{3}{ }^{3}, \mathrm{C}$, Chang-Hu $\mathrm{Lu}^{2}$ and \\ Si-Chong Chen ${ }^{5}$ (D) \\ 1 Institute of Applied Ecology, College of Food Science, Nanjing Xiaozhuang University, Nanjing 211171, \\ Jiangsu, China \\ 2 College of Biology and Environmental Science, Nanjing Forestry University, Nanjing 210037, Jiangsu, China; \\ zhengw1028@163.com (Z.W.); changhul@163.com (C.-H.L.) \\ 3 Institute of Zoology, Chinese Academy of Sciences, Beijing 100044, China; lixh@ioz.ac.cn (X.-H.L.); \\ yanchuan@ioz.ac.cn (C.Y.) \\ 4 College of Life Science, Qufu Normal University, Qufu 273100, Shandong, China; ympclong@163.com \\ 5 Royal Botanic Gardens, Kew, Wakehurst Place, West Sussex RH17 6TN, UK; chensichong0528@gmail.com \\ * Correspondence: lining196@126.com; Tel.: +86-25-86178307
}

Received: 29 July 2019; Accepted: 9 September 2019; Published: 11 September 2019

check for updates

\begin{abstract}
Biodiversity is rapidly decreasing worldwide. Its great importance has been attached to conservation through in-situ and ex-situ management. Animal-mediated seed dispersal is an important ecological process, linking the threatened plants and animal partners in ex-situ habitats, and in turn affecting tree conservation. However, how bird traits affect seed dispersal within in-situ and ex-situ conservation still remains unclear. Here, we aim to answer this question. We tested whether bird traits affect seed deposition and seedling recruitment. Our results showed that 19 bird species foraged and removed Taxus chinensis (Pilger) Rehd. seeds across botanical gardens (ex-situ) and natural reserves (in-situ). The seed dispersal pattern of $T$. chinensis varied in the stages of seed removal and seed deposition, but showed no significant difference in the seedling recruitment stage. This showed that bird morphological and behavioral traits affected seed dispersal through the different contributions of varying bird species. Large birds and their high visitation frequency played a central role in seed removal patterns. The frequency of post-foraging habitat use was the most important factor determining the role of birds in seed deposition and the following seedling recruitment. Urocissa erythrorhyncha and Chloropsis hardwickii played the role of keystone species in seed deposition and seedling recruitment, respectively. Our results highlight the importance of bird traits in facilitating the seed dispersal of trees within in-situ and ex-situ conservation, which should be considered in future forest conservation and management.
\end{abstract}

Keywords: bird traits; seed dispersal; in-situ; ex-situ; forest management

\section{Introduction}

Biodiversity is rapidly decreasing worldwide due to habitat loss, climate change, and other ecological drivers [1-3]. Many plant species in natural forests are threatened with extinction [4-6]. Some of these threatened species have been introduced into new areas, such as botanical gardens for ex-situ conservation [7-9]. The importance of in-situ and ex-situ conservation of endangered plants is widely recognized [4-6]. The success of ex-situ conservation is often facilitated by establishing mutualistic interactions between the introduced threatened plant and the local animal 
community $[10,11]$. One of the most important mutualisms is animal-mediated seed dispersal, which influences the regeneration of plant species and the persistence of plant communities [10].

Bird-mediated seed dispersal links the introduced threatened plant and native birds in the new habitat; thereby, playing a key role in the regeneration success of the endangered plant [12-14]. A quantitative understanding of bird traits, which can affect the recruitment of plant populations and communities in natural habitats, is crucial for predicting the contribution of dispersal vectors across plant recruitment stages $[12,15,16]$. The contribution of bird traits to seed dispersal is influenced by both morphological and behavioral traits. From the perspective of morphological traits, large-sized birds could be the key species in seed dispersal because, compared to small ones, they often forage on a large number of fruits [17-19] and disperse seeds over long distances [20-22]. Post-foraging habitat use is an important behavioral trait for exploring the role of bird species in seed deposition. The microsites preferred by birds as feeding habitats and shelters will receive more deposited seeds than other sites [23-25]. Increasing scientific evidence shows that plants in ex-situ conservation form new mutualistic interactions in new habitats, and their seed dispersal is affected by the traits of their new avian partners. However, there is still a lack of empirical information on how bird traits affect seed dispersal in in-situ and ex-situ sites, and whether these traits facilitate the process of seed dispersal.

Here, we quantified the effects of bird traits on the seed removal, seed deposition, and seedling recruitment of Taxus chinensis (Pilger) Rehd. in a botanical garden (ex-situ conservation) and a natural forest (in-situ conservation). We hypothesized that the seed removing ability of different bird dispersers varied according to the pattern associated with the traits of frugivorous birds (e.g., body size), and specifically predicted that more seeds would be removed by larger species across the in-situ and ex-situ sites. We expected bird post-foraging behaviors to be similar in the in-situ and ex-situ sites, which could lead to similar patterns in seedling recruitment in both sites. We also discussed the prevalence and importance of bird traits in plant regeneration with different conservation management methods.

\section{Materials and Methods}

\subsection{Study Species and Sites}

T. chinensis, an endemic and relic tree species in China, has been listed as an endangered species by International Union for Conservation of Nature and a first-class national protected species by the Chinese government.

We selected an in-situ population and an ex-situ population of T. chinensis. The in-situ site was in Guihe village, located in the southern experimental area of the Meihua Mountain National Nature Reserve in Fujian Province ( $25^{\circ} 15^{\prime}-25^{\circ} 35^{\prime}$ N, $116^{\circ} 45^{\prime}-116^{\circ} 57^{\prime}$ E; Area: 22,169 ha). At the time of the study, it had ten female trees and three male trees scattered in evergreen broad-leaved forest [11]. For ex-situ conservation, 11 saplings were introduced from its original area Lu Mountain, Jiangxi Province to the Nanjing Botanical Garden Memorial Sun Yat-Sen, Jiangsu Province in the $1950 \mathrm{~s}\left(32^{\circ} 5^{\prime} \mathrm{N}\right.$, $118^{\circ} 48^{\prime}$ E; Area: 186 ha) [26]. The ex-situ site had ten female trees and four male trees scattered in evergreen broad-leaved forest [26].

\subsection{Seed Dispersal in In-Situ and Ex-Situ Sites}

To compare seed dispersal across the in-situ and ex-situ sites, we quantified how frequently birds visited the mature trees of $T$. chinensis, and how many seeds were foraged and removed. We chose five mature trees, respectively, across the two sites, and observed the foraging behavior of birds from the opposite mountain slopes, at a distance of around $50 \mathrm{~m}$, using a telescope (Leica 70, Leica Microsystems GMBH, Mannheim, Germany). The birds that visited a mother tree were observed from landing to leaving [25]. The observations lasted $8 \mathrm{~h}$ per $\mathrm{d}$ during the fruiting seasons of T. chinensis, from late October to early December, accounting for 75 days annually from 2016 to 2018 . We identified and counted the frugivorous bird species, and also recorded the number of seeds removed. 
To study the contribution of birds to seed deposition and future seedling recruitment, post-foraging habitat selection and usage frequency of the dominant bird species were observed. We observed the post-foraging perching habitats of individual birds every $60 \mathrm{~s}$, until the bird flew out of our sight. Moreover, fifteen $1 \mathrm{~m}^{2}$ quadrats of perching habitats for each bird species (a total of 45 quadrats for three species at each site) were identified, and the frequency of bird habitat use was counted. Every day, we counted the number of regurgitated seeds from the quadrats. At the end of the fruiting seasons in 2017 and 2018, we counted the number of newly emerged 1 year old seedlings in each quadrat, to determine seedling recruitment.

For the purpose of comparing seed dispersal patterns, we used the $t$-test to compare seed removal (visiting frequency and the number of seeds removed), the number of deposited seeds, and 1 year old seedlings between the in-situ and ex-situ sites. We also developed a network to show the plant-bird interactions across the two sites, in which the strength of the interaction depended on the number of seeds removed by the birds.

\subsection{Effects of Bird Traits on Seed Dispersal in In-Situ and Ex-Situ Sites}

We selected two behavioral traits (foraging visitation frequency and frequency of post-foraging habitat use) and six morphological traits (bill length, body length, body weight, wing length, tail length, and tarsus length) to investigate the effect of bird traits on seed dispersal [27]. To obtain the morphological traits of the local bird species, we measured five males and five females of each bird species using the specimens preserved in the Museum of Nanjing Forestry University [28]. We used the mean value of each trait for analyses. Furthermore, we compared six morphological traits of frugivorous bird species by ANOVA test after the data log-transformed to approximate normality; size effects were removed in all cases by using residuals from the regressions on body length (snout-vent length, SVL).

To test the role of bird traits in seed removal, we used the Random Forest (RF) algorithm to plot the partial effects of bird visitation frequency, three morphological traits (bill length, body weight, and body length), study sites, and study years on the number of seeds removed (R package Random Forest). For seed deposition and seedling recruitment, the RF algorithm was used to plot the partial effects of frequency of post-foraging habitat use, five morphological traits (body weight, body length, wing length, tail length, and tarsus length), study sites, and study years on the number of deposited seeds and newly emerged 1 year old seedlings, respectively. Moreover, the number of deposited seeds and seedlings in the habitats were also explained by the generalized liner mixed model (GLMM), where bird traits, species, and post-foraging habitat use were the covariates and the study years, and their interaction term was treated as the random effects. We used the glmer function in the R Ver. 3.1.2 package 'Ime4' for the analysis. As the number of seeds and seedlings are count data, the models were fitted with a Poisson distribution.

\section{Results}

The number of bird species that foraged and removed T. chinensis seeds across the in-situ and ex-situ sites was recorded as twelve and seven, respectively (Table 1, Figure 1). Only the body length (ANOVA test: $F_{1,17}=5.277, p=0.035$ ) of the bird species varied between the two habitats. The other five traits, including body weight (ANOVA test: $F_{1,17}=0.744, p=0.400$ ), wing length (ANOVA test: $F_{1,17}=2.923, p=0.106$ ), tail length (ANOVA test: $F_{1,17}=0.401, p=0.535$ ), bill length (ANOVA test: $F_{1,17}=0.601, p=0.449$ ), and tarsus length (ANOVA test: $F_{1,17}=3.174, p=0.093$ ), showed no significant differences between the in-situ and ex-situ sites (Figure 2). Although frugivorous bird species foraged T. chinensis seeds in the in-situ site, they foraged more seeds in the ex-situ site, as they visited the ex-situ site more ( $t$-test: $t=2.26, p=0.02)$ than the in-situ site. Furthermore, the most common disperser species were different between the two sites; Pycnonotus sinensis, Urocissa erythroryncha, and Cyanopica cyanus were the most common foragers, contributing to $99.48 \%$ of seed removal, in the ex-situ site, whereas Chloropsis hardwickii, Hemixos castanonotus, and Hypsipetes mcclellandii were the most 
common foragers, contributing to $77.01 \%$ of seed removal, in the in-situ site. Bird visitation frequency, body length, and body weight positively correlated to the number of seeds removed (RF algorithm, Figure 3a), indicating that the visitation frequency of the large birds was important in shaping the seed removal patterns across different sites.

Table 1. Seed removal by frugivorous birds in three years (2016-2018) across in-situ and ex-situ sites, southeast China.

\begin{tabular}{ccccc}
\hline Sites & $\begin{array}{c}\text { Number of Bird } \\
\text { Species }\end{array}$ & $\begin{array}{c}\text { Mean Visitation } \\
\text { Frequency }\end{array}$ & $\begin{array}{c}\text { Mean Number of } \\
\text { Seed Removal }\end{array}$ & $\begin{array}{c}\text { Total Number of } \\
\text { Seed Removal }\end{array}$ \\
\hline In-situ forest & 12 & $11.00 \pm 1.98$ & $121.42 \pm 28.55$ & 4371 \\
Ex-situ forest & 7 & $87.81 \pm 33.91$ & $477.62 \pm 176.34$ & 10,030 \\
\hline
\end{tabular}

Results are presented as means \pm standard error.

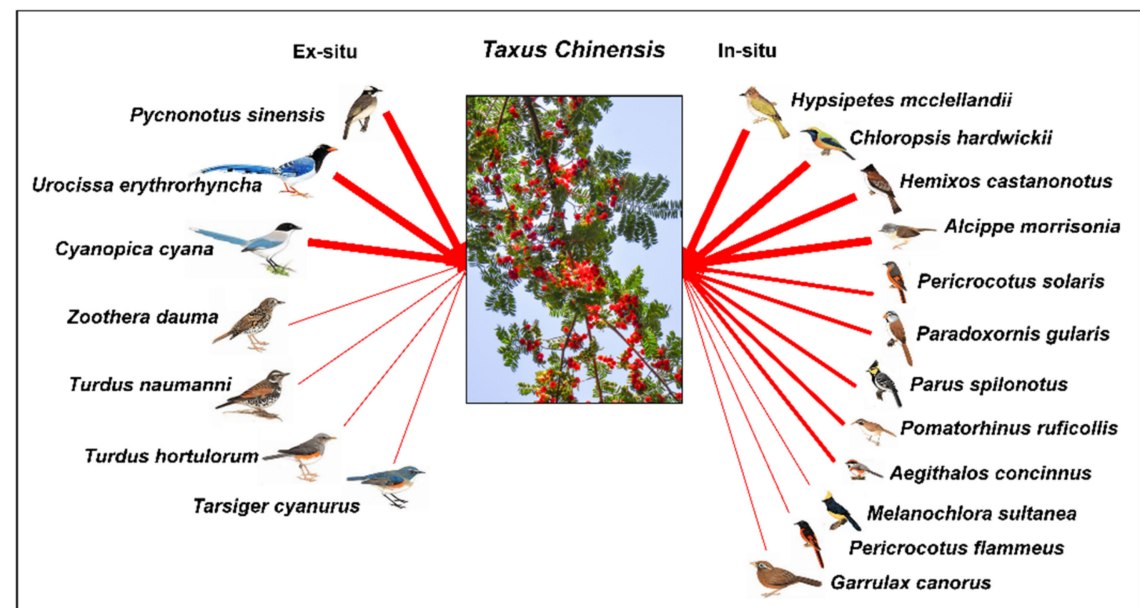

Figure 1. A network approach showing seed dispersal interaction between Taxus chinensis (Pilger) Rehd and frugivorous birds across in-situ and ex-situ sites, Southeast China. Line thickness represents interaction strength, based on the number of seeds removed. Bird pictures are cited from the A Field Guide to the Birds of China [29].
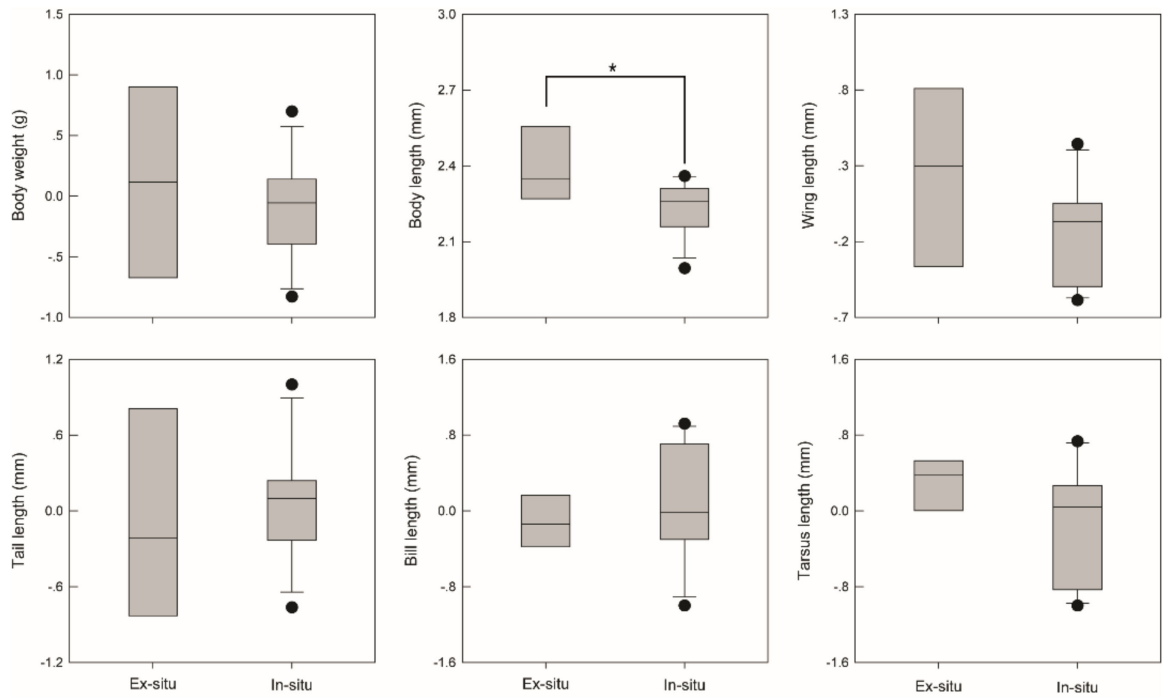

Figure 2. Comparing the morphological traits of foraging partners of Taxus chinensis (Pilger) Rehd across in-situ and ex-situ sites, Southeast China (ANOVA with data log transformed). Size effects were removed in all cases by using residuals from the regressions on body length (snout-vent length, SVL). Values are presented as mean \pm standard error. ${ }^{*} p=0.05$. 


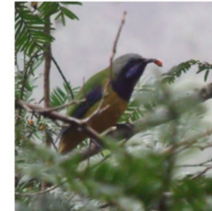

(a) Seed removal

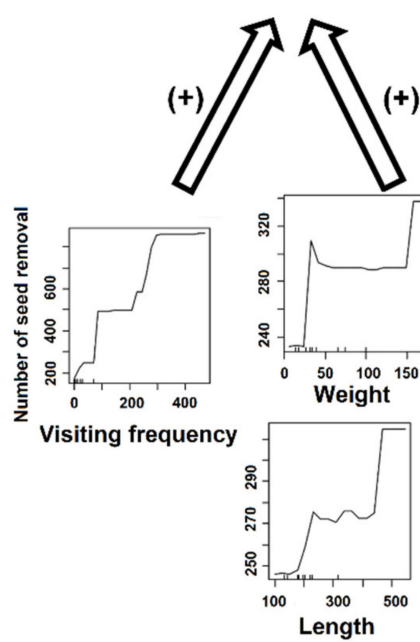

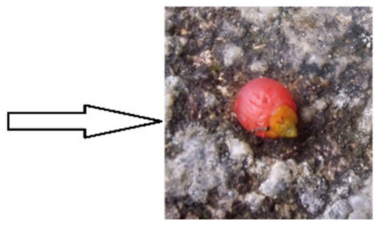

(b) Seed deposition
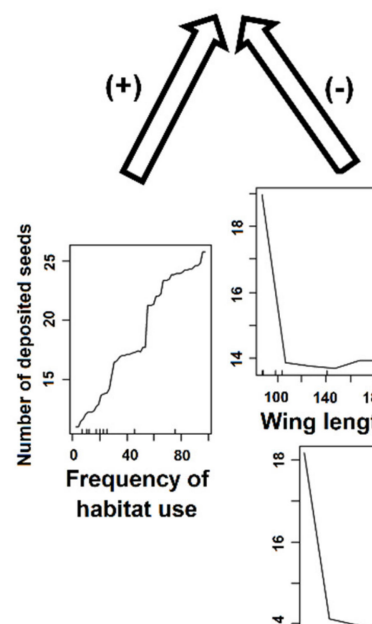

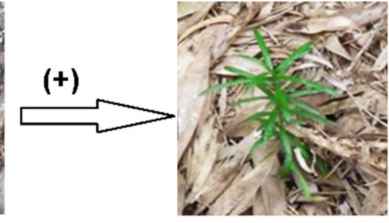

(c) Seedling recruitment

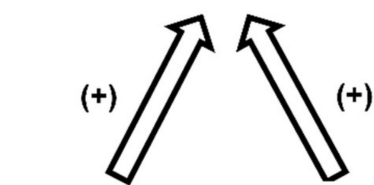

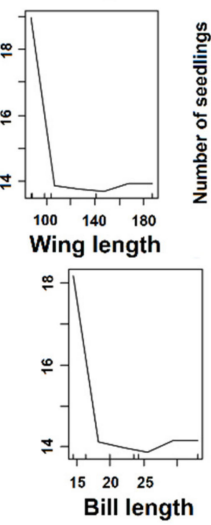

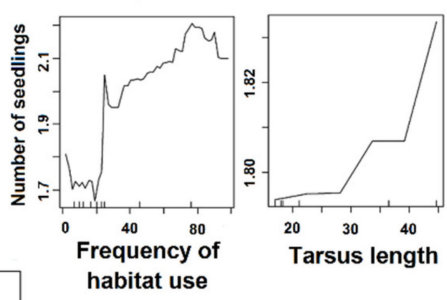

Figure 3. A machine-learning algorithm, random forest, for testing the effects of bird traits on (a) seed removal, (b) seed deposition, (c) seedling recruitment for Taxus chinensis (Pilger) Rehd across the in-situ and ex-situ sites, Southeast China.

In the case of seed deposition, the number of bird-deposited seeds was significantly higher ( $t$-test: $t=-5.32, p=0)$ in the in-situ site (1750) than in the ex-situ site (882). The number of deposited seeds increased with the frequency of post-foraging habitat use, and decreased with bill and wing length (Figure 3b). Furthermore, the GLMM not only highlighted the role of frequency of bird post-foraging habitat use and wing length, but also confirmed the contribution of $U$. erythrorhyncha to the number of deposited seeds (Table 2). In the case of seedling recruitment, the number of 1-year-old seedlings showed no significant difference between the in-situ and ex-situ sites (75 and 86 seedlings in the in-situ and ex-situ sites, respectively; $t$-test: $t=-0.85, p=0.20$ ). However, the number of 1 -year-old seedlings positively correlated to the frequency of post-foraging habitat use, number of deposited seeds, and tarsus length (Figure 3c). Furthermore, the GLMM highlighted the role of the number of deposited seeds for seedling recruitment, and verified the contribution of $C$. hardwickii for the future regeneration pattern (Table 2).

Table 2. Analyzing the effects of bird traits on the seed deposition and seedling recruitment of the endangered Taxus chinensis (Pilger) Rehd across in-situ and ex-situ sites (generalized linear mixed-effects models with a Poisson distribution).

\begin{tabular}{ccccc}
\hline Parameter & Estimate & Standard Error & $\mathrm{Z}$ & $p$ \\
\hline Intercept & Effects of bird traits on seed deposition & & \\
Frequency of habitat use & 4.820 & 0.950 & 5.073 & $3.92 \mathrm{e}^{-7}$ \\
Wing length & 0.018 & 0.002 & 9.232 & $<2 \mathrm{e}^{-16 * *}$ \\
Habitat use by Urocissa erythrorhyncha & -0.027 & 0.009 & -2.992 & $0.003^{* *}$ \\
Sites & 2.472 & 0.850 & 2.908 & $0.004^{* *}$ \\
Random effects & -0.240 & 0.100 & -2.396 & $0.016^{*}$ \\
Groups & Variance & Std. Dev. & \\
Years & 0.004 & 0.061 & \\
\hline
\end{tabular}


Table 2. Cont.

\begin{tabular}{|c|c|c|c|c|}
\hline Parameter & Estimate & Standard Error & $\mathbf{Z}$ & $p$ \\
\hline \multicolumn{5}{|c|}{ Effects of bird traits on seedling recruitment } \\
\hline Intercept & -2.305 & 2.257 & -1.021 & 0.307 \\
\hline Number of deposited seeds & 0.024 & 0.012 & 2.124 & 0.034 * \\
\hline Habitat use by Chloropsis hardwickii & 0.846 & 0.374 & 2.263 & 0.023 * \\
\hline Sites & 0.033 & 0.271 & 0.125 & 0.901 \\
\hline \multicolumn{5}{|l|}{ Random effects } \\
\hline Groups & Variance & Std. Dev. & & \\
\hline Years & 0 & 0 & & \\
\hline
\end{tabular}

\section{Discussion}

Our comparative results show that the number of seeds removed and deposited varied between the in-situ and ex-situ sites; however, T. chinensis exhibited similar seedling recruitment across both sites. The seed dispersal patterns of T. chinensis across the two sites were affected by bird traits. Large birds and their visiting frequency strongly affected seed removal and seed deposition. The frequency of post-foraging habitat use was the most important factor determining the role of frugivorous birds in seedling recruitment. Most importantly, our results highlight the contribution of two bird species, U. erythrorhyncha and C. hardwickii, to seed deposition and seedling recruitment, respectively.

As expected, more bird species were involved in the bird-T. chinensis interaction in the in-situ site than in the ex-situ site, which was strongly affected by the habitat structures of the two sites. The structure of most ex-situ sites consists of simple botanical gardens [11] with dominant artificial plants, which are less attractive to bird species for foraging [30]. However, a higher number of large bird species were involved in the T. chinensis-bird interaction in the ex-situ site, resulting in higher seed removal rates because large birds need more energy than smaller birds to make their foraging efforts more profitable $[16,17,31]$. Moreover, the visiting frequency of the birds also affected the seed removal number across the two sites. Fruit trees were scattered in the ex-situ habitat, which supplied a unique food resource for the birds, resulting in a high seed removal rate [29,32-34]. More deposited seeds were found in the in-situ habitat owing to its high seed removal rate.

As there was no significant difference in the number of 1 year old seedlings between the in-situ and ex-situ sites, it can be implied that the ex-situ T. chinensis plants have a similar regeneration ability as the in-situ plants. The similarity in the regeneration ability of $T$. chinensis across both sites could be due to both sites possessing similar conditions (evergreen broad-leaf forest). Evergreen broad-leaf forest supplies a safe shelter for birds [11,25], resulting in lots of seeds being deposited into the forest; thereby, affecting the future seedling recruitment. The behavioral traits of birds were found to affect future seedling recruitment, not only in our study system, but also in desert ecosystems [18], fragmented forests [35], and natural forests [20].

Our results also highlight the role of two bird species in enhancing the seed deposition and seedling recruitment of $T$. chinensis. It is not surprising that $U$. erythrorhyncha facilitates seed deposition in the ex-situ site, as it is a large generalist species with a high tolerance for disturbance, thus was clearly placed in the bird-T. chinensis interaction $[11,26]$. Moreover, the behavioral traits of $C$. hardwickii enhanced the number of seedlings in the in-situ site, which was confirmed by the thesis of "directed dispersal" [36]. The spatial consistency between bird habitat and seedling recruitment habitat highlights the role of bird contributions to plant recruitment.

\section{Conclusions}

From the point of view of conservation biology, our results show the important influence of frugivorous birds in facilitating the regeneration of trees in ex-situ sites. Seed dispersal has been widely recognized as a key process within forests, where plants are newly introduced, and determines the 
conservation success of ex-situ plants $[6,11,37]$. We also expect different microevolutionary patterns for $T$. chinensis across the in-situ and ex-situ sites depending on this relationship. More importantly, our comparative results on seed dispersal across in-situ and ex-situ sites highlight the importance of frugivorous birds for conservation action. Our study also supports the idea that avian frugivores serve as stepping stones for ex-situ trees to thrive throughout in-situ and ex-situ sites. Traits of frugivorous birds facilitate seed dispersal of ex-situ and in-situ trees. In the bird-T. chinensis interaction, seed dispersal is not only affected by the body size of birds, but also influenced by their behavioral traits. Our results highlight the role of two common species (U. erythrorhyncha and C. hardwickii) in seed deposition and seedling recruitment. Although common species are not of concern or protected by society and the government, their ecological function should not be ignored. We suggest the function of common species should also be studied and considered in in-situ and ex-situ conservation management. Finally, we advocate integrated species-trait management to maintain, and even increase, the presence of large frugivorous birds in ex-situ conservation. This is expected to accelerate re-establishment of interaction between ex-situ trees and native birds, which should be considered for future ex-situ conservation strategies.

Author Contributions: N.L., Z.W., X.-H.Y., and C.-H.L. designed the study. N.L. and C.-H.L. selected the study site and organized field work. N.L. managed project administration and led the manuscript writing, with contributions from all the authors.

Funding: This research was funded by the National Natural Science Foundation of China, grant number 31700468 and the Natural Science Foundation of Jiangsu Province, grant number BK2017636.

Acknowledgments: We thank Lin Zhang for helping with previewing the manuscript.

Conflicts of Interest: The authors declare no conflicts of interest.

\section{References}

1. Cardinale, B.J.; Duffy, J.E.; Gonzalez, A.; Hooper, D.U.; Perrings, C.; Venail, P.; Narwani, A.; Mace, G.M.; Tilman, D.; Wardle, D.A.; et al. Biodiversity loss and its impact on humanity. Nature 2012, 486, 59-67. [CrossRef] [PubMed]

2. Oliver, T.H.; Heard, M.S.; Isaac, N.J.B.; Roy, D.B.; Procter, D.; Eigenbrod, F.; Freckleton, R.; Hector, A.; Orme, C.L.; Petchey, O.L.; et al. Biodiversity and resilience of ecosystem functions. Trends Ecol. Evol. 2015, 30, 673-684. [CrossRef] [PubMed]

3. Fanin, N.; Gundale, M.J.; Farrell, M.; Ciobanu, M.; Baldock, J.A.; Nilsson, M.C.; Kardol, P.; Wardle, D.A. Consistent effects of biodiversity loss on multifunctionality across contrasting ecosystems. Nature Ecol. Evol. 2018, 2, 269-278. [CrossRef] [PubMed]

4. Carroll, S.P.; Fox, C.W. Conservation Biology Evolution in Action; Oxford University Press: New York, NY, USA, 2008.

5. Braverman, I. Conservation without nature: The trouble with in situ versus ex situ conservation. Geoforum 2014, 51, 47-57. [CrossRef]

6. Primack, R.B. Essentials of Conservation Biology, 6th ed; Oxford University Press: New York, NY, USA, 2014.

7. Guerrant, E.O.; Havens, K.; Vitt, P. Sampling for effective ex situ plant conservation. Int. J. Plant Sci. 2014, 175, 11-20. [CrossRef]

8. Guerrant, E.O.; Havens, K.; Maunder, M. Ex Situ Plant Conservation: Supporting Species Survival in the Wild; Island Press: Washington, DC, USA, 2004.

9. Oldfield, S.F. Botanic gardens and the conservation of tree species. Trends Plant Sci. 2009, 14, 581-583. [CrossRef] [PubMed]

10. Bascompte, J.; Jordano, P. Plant-animal mutualistic networks: The architecture of biodiversity. Ann. Rev. Ecol. Evol. Syst. 2007, 38, 567-593. [CrossRef]

11. Li, N.; An, S.Q.; Liu, Z.; Lu, C.H. Fruit consumption and seed dispersal by birds in native vs. ex-situ individuals of the endangered Chinese yew, Taxus chinensis. Ecol. Res. 2014, 29, 917-923.

12. Gosper, C.R.; Stansbury, C.D.; Vivian-Smith, G. Seed dispersal of fleshy-fruited invasive plants by birds: Contributing factors and management options. Divers. Distrib. 2005, 11, 549-558. [CrossRef] 
13. Aslan, C.E. Implications of newly-formed seed-dispersal mutualisms between birds and introduced plants in northern California, USA. Biol. Invasions 2011, 13, 2829-2845. [CrossRef]

14. Schleuning, M.; Fründ, J.; García, D. Predicting ecosystem functions from biodiversity and mutualistic networks: An extension of trait-based concepts to plant-animal interactions. Ecography 2015, 38, 380-392. [CrossRef]

15. Bregman, T.P.; Lees, A.C.; MacGregor, H.E.A.; Darski, B.; de Moura, N.G.; Aleixo, A.; Barlow, J.; Tobias, J.A. Using avian functional traits to assess the impact of land-cover change on ecosystem processes linked to resilience in tropical forests. Proc. R. Soc. Lond. B 2016, 283, 1289. [CrossRef] [PubMed]

16. Muñoz, M.C.; Schaefer, H.M.; Böhning-Gaese, K.; Schleuning, M. Importance of animal and plant traits for fruit removal and seedling recruitment in a tropical forest. Oikos 2017, 126, 823-832. [CrossRef]

17. Jordano, P.; Schupp, E.W. Determinants of seed disperser effectiveness: The quantity component and patterns of seed rain for Prunus mahaleb. Ecol. Monog. 2000, 70, 591-615. [CrossRef]

18. Spiegel, O.; Nathan, R. Incorporating dispersal distance into the disperser effectiveness framework: Frugivorous birds provide complementary dispersal to plants in a patchy environment. Ecol. Lett. 2007, 10, 718-728. [CrossRef] [PubMed]

19. Chen, S.C.; Moles, A.T. A mammoth mouthful? A test of the idea that larger animals disperse larger seeds. Glob. Ecol. Biogeog. 2015, 24, 1269-1280.

20. Wotton, D.M.; Kelly, D. Do larger frugivores move seeds further? Body size, seed dispersal distance, and a case study of a large, sedentary pigeon. J. Biogeogr. 2012, 39, 1973-1983.

21. Farwig, N.; Schabo, D.G.; Albrecht, J. Trait-associated loss of frugivores in fragmented forest does not affect seed removal rates. J. Ecol. 2017, 105, 20-28. [CrossRef]

22. Zwolak, R. How intraspecific variation in seed-dispersing animals matters for plants. Biol. Rev. 2017. [CrossRef]

23. Puerta-Piñero, C.; Pino, J.; Gómez, J.M. Direct and indirect landscape effects on Quercus ilex regeneration in heterogeneous environments. Oecologia 2012, 170, 1009-1020. [CrossRef]

24. Côrtes, M.; Uriarte, M. Integrating frugivore behavior and animal movement: A review of the evidence and implication for scaling seed dispersal. Biol. Rev. 2013, 88, 255-272. [CrossRef] [PubMed]

25. Li, N.; Wang, Z.; Zhang, S.; Yan, C.; Li, X.H.; Lu, C.H. Importance of bird traits for seed dispersal patterns of co-fruiting trees in a patchy forest. Integr. Zool. 2018. [CrossRef] [PubMed]

26. Li, N.; An, S.Q.; Fu, W.Y.; Lu, C.H. Ecological rescue of remnant fengshui trees in farmlands by avian frugivores. Plant Ecol. Diver. 2015, 8, 401-405. [CrossRef]

27. Moermond, T.C.; Denslow, J.S. Neotropical avian frugivores: Patterns of behavior, morphology, and nutrition, with consequences for fruit selection. Ornithol. Monogr. 1985, 36, 865-897. [CrossRef]

28. Dehling, D.M.; Fritz, S.A.; Töpfer, T.; Päckert, M.; Estler, P.; Böhning-Gaese, K.; Schleuning, M. Functional and phylogenetic diversity and assemblage structure of frugivorous birds along an elevational gradient in the tropical Andes. Ecography 2014, 37, 1047-1055. [CrossRef]

29. MacKinnon, J.R.; Phillipps, K.; He, F.Q. A Field Guide to the Birds of China; Oxford University Press: New York, NY, USA, 2000.

30. Breitbach, N.; Laube, I.; Steffan-Dewenter, I.; Bohning-Gaese, K. Bird diversity and seed dispersal along a human land-use gradient: High seed removal in structurally simple farmland. Oecologia 2010, 162, 965-976. [CrossRef] [PubMed]

31. Herrera, C.M. Vertebrate frugivores and their interaction with invertebrate fruit predators: Supporting evidence a Costa Rican dry forest. Oikos 1989, 54, 185-188. [CrossRef]

32. Holbrook, K.M.; Smith, T.B.; Hardesty, B.D. Implications of long-distance movements of frugivorous rain forest hornbills. Ecography 2002, 25, 745-749. [CrossRef]

33. Eshiamwata, G.E.; Berens, D.G.; Bleher, B.; Dean, W.R.J.; Bohning-Gaese, K. Bird assemblages in isolated Ficus trees in Kenyan farmland. J. Trop. Ecol. 2006, 22, 723-726. [CrossRef]

34. Herrera, J.M.; Morales, J.M.; García, D. Differential effects of fruit availability and habitat cover for frugivore-mediated seed dispersal in a heterogeneous landscape. J. Ecol. 2011, 99, 1100-1107. [CrossRef]

35. Mueller, T.; Lenz, J.; Caprano, T.; Fiedler, W.; Böhning-Gaese, K. Large frugivorous birds facilitate functional connectivity of fragmented landscapes. J. Appl. Ecol. 2014, 51, 684-692. [CrossRef] 
36. Howe, H.F.; Smallwood, J. Ecology of seed dispersal. Annu. Rev. Ecol. Syst. 1982, 13, 201-228. [CrossRef]

37. Charco, J.; Venturas, M.; Gil, L.; Nanos, N. Effective Seed Dispersal and Fecundity Variation in a Small and Marginal Population of Pinus pinaster Ait. Growing in a Harsh Environment: Implications for Conservation of Forest Genetic Resources. Forests 2017, 8, 312. 